TITLE:

\title{
MicroRNAs in Barrett's esophagus and esophageal adenocarcinoma
}

$\operatorname{AUTHOR}(\mathrm{S})$ :

Kan, Takatsugu; Meltzer, Stephen J.

CITATION:

Kan, Takatsugu ... [et al]. MicroRNAs in Barrett's eso phagus and

esophageal adenocarcinoma. Current Opinion in Pharmacology 2009, 9(6): 727-732

ISSUE DATE:

2009-12

URL:

http://hdl.handle.net/2433/88219

RIGHT:

c 2009 Elsevier Ltd. All rights reserved.; This is not the published version. Please cite only the published version.; この論文は出版社版でありませ ん。引用の際には出版社版をご確認ご利用ください。 


\section{$<$ Title $>$}

MicroRNAs in Barrett's esophagus and esophageal adenocarcinoma

$<$ Short Title $>$

miRNAs and esophageal neoplasms

\section{<Authors>}

Takatsugu $\operatorname{Kan}^{1}$, Stephen J. Meltzer ${ }^{2 *}$

1. Department of Surgery, Kyoto University Hospital.

Kawara-cho 54, Shogoin, Kyoto City, 606-8507, Japan.

tsugu@kuhp.kyoto-u.ac.jp

2: Division of Gastroenterology, Departments of Medicine and Oncology, The Johns Hopkins University School of Medicine and Sidney Kimmel Comprehensive Cancer Center.

1503 E. Jefferson St. Baltimore MD 21287

meltzer@jhmi.edu

*: corresponding author 


\section{$<$ Summary $>$}

The molecular genetics of Barrett's esophagus (BE) and its evolution to esophageal adenocarcinoma (EAC) have been widely studied; however, the molecular mechanism of BE-EAC carcinogenesis has not been completely understood. MicroRNA (miRNA) is now essential to understand the molecular mechanism of cancer progression. Recent findings include the following: firstly, miRNA expression profiles can distinguish between BE and EAC; secondly, miR-196a is upregulated in EAC tissues targeting annexin A1, thereby exerting antiapoptotic effects and contributing to EAC cell survival; miR-196a may also constitute a good biomarker of progression during BE-EAC carcinogenesis; and thirdly, The miR-106b-25 polycistron is activated by genomic amplification and is involved in esophageal neoplastic progression and proliferation via the suppression of two target genes, p21 and Bim.

\section{$<$ Introduction $>$}

Barrett's esophagus (BE) is a metaplastic condition in which the normal squamous epithelium of the lower esophagus is replaced by a small intestinal-like columnar lining [1 A.J. Cameron, Management of Barrett's esophagus, Mayo Clin Proc 73 (1998), pp. 457-461. View Record in Scopus | Cited By in Scopus (44)1]. BE starts as a noncancerous metaplastic lesion and may progress to low-grade dysplasia (LGD), high-grade dysplasia (HGD), and finally to frank esophageal adenocarcinoma (EAC). Although the molecular basis of BE and its evolution to EAC have been widely studied [[2], [3], [4] and [5]], molecular mechanisms of BE-EAC carcinogenesis have not yet been completely elucidated. Improved biomarkers and a better understanding of the mechanisms of this neoplastic progression are therefore eagerly awaited. 
MicroRNA (miRNA) is a newly discovered class of abundant, small, naturally occurring RNAs. miRNA inactivates multiple target genes by sequence-specific binding-mediated destabilization of mRNA or inhibition of translation. Although the first miRNA, lin-4, was discovered in 1993 and the second miR, let-7, in 2000 in Caenorhabditis elegans, only recently has the study of this class of small regulatory RNAs in humans become more widespread. Experimental evidence accumulating in recent years has led oncologists to speculate that unrevealed molecular actors, particularly noncoding RNAs previously been classified as ‘junk,' play important roles in carcinogenesis. In fact, as much as $70 \%$ or more of the genome has been found to be transcribed in mammals [6]. Thus, it is a natural extension of this logic to explore novel noncoding RNA-based mechanisms underlying cancer-related gene dysregulation. miRNAs have been intensively studied in cancer research, and these molecules are predicted to control as much as $30 \%$ of all gene expression alteration [7]. miRNA regulatory mechanisms involved in cancer progression may be viewed as previously missing pieces of a puzzle that are now essential to mapping the molecular landscape of cancer progression. Experimental evidence has contributed to the understanding of molecular mechanisms of miRNAs not only in cancers in general, but also specifically in BE and EAC in particular.

In this review, we highlight three issues of current relevance to this field and discuss firstly, recent findings regarding the taxonomy, biogenesis, and functions of miRNA; secondly, some of the latest findings on the molecular mechanisms of miRNA involved in BE and EAC; and thirdly, the therapeutic-clinical potential of miRNAs in BE-EAC neoplastic progression. 


\section{Surveillance of BE and EAC.}

$\mathrm{BE}$ is a premalignant condition that predisposes individuals to the development of EAC, one of the most rapidly increasing cancers in developed nations [8]. Estimates of the prevalence of BE range from 0.9\% to 4.5\% [[9] and 10 W.K. Hirota, T.M. Loughney, D.J. Lazas, C.L. Maydonovitch, V. Rholl and R.K. Wong, Specialized intestinal metaplasia, dysplasia, and cancer of the esophagus and esophagogastric junction: prevalence and clinical data, Gastroenterology 116 (1999), pp. 277-285. Abstract | View Record in Scopus | Cited By in Scopus (308)[10]]. A recent study in Sweden revealed that BE had a prevalence of 1.6\% (of 21610 patients) [11], implying that more than three million individuals may harbor BE in the United States alone [12]. Among these patients, EAC susceptibility is a life-threatening long-term sequela. The incidence of EAC in BE is estimated 1.8 per 1000 person-years, 30-fold higher than in the general population [13]. It is recommended that BE patients undergo surveillance endoscopy. However, histology-based surveillance is insufficient because of poor reliability of the histological grading of BE [14•] and poor specificity to predict the progression to cancer [15]. Moreover, although EAC is frequently accompanied by Barrett's metaplasia, only approximately 5\% of patients presenting with EAC have an antecedent diagnosis of Barrett's metaplasia [16]. Thus, the majority of patients presenting with EAC will therefore not benefit from refinements to endoscopic surveillance programs for Barrett's metaplasia.

The molecular genetics of BE and its evolution to EAC have been widely studied. However, this process still needs to be better understood in order to provide firstly, clues to biologic pathways underlying BE-associated 
neoplastic transformation; secondly, biomarkers of early cancer detection, disease progression, or ultimate prognosis; and thirdly, therapeutic strategies to prevent and treat this disease process.

\section{Taxonomy, biogenesis and functions of the miRNA}

Various noncoding small RNAs with distinctive characteristics have been found. It is widely believed that there are three categories of noncoding small RNAs, based on their mechanism of biogenesis and the type of Argonaute protein they are associated with. These three categories are miRNAs, endogenous small interfering RNAs (endo-siRNAs or esiRNAs), and Piwi-interacting RNAs (piRNAs) [17•]. miRNAs are a class of abundant, approximately 22-nucleotide, noncoding small RNAs that mediate post-transcriptional regulation of their cognate target mRNAs. Figure 1 illustrates the biogenesis of miRNA. Nascent miRNA (pri-miRNA) is generated by RNA polymerase II [18] or III [19] and processed within the nucleus into approximately 70nucleotide incomplete stem-loop RNA (pre-miRNA) by the RNase III endonuclease Drosha and DGCR8 (Drosha/DGCR8 complex) [20]. Exportin 5 transports pre-miRNA from the nucleus to the cytoplasm. The cytoplasmic RNase III Dicer then cuts pre-miRNA into a 19-22-base long RNA duplex [21]. RISC (the RNAinduced silencing complex) incorporates the short RNA duplex and activates one strand of RNA (mature miRNA) while the other strand is degraded [17•]. The biological role of miRNA is to inactivate single or multiple target genes by sequence-specific binding-mediated mechanisms. Figure 1. Biogenesis of the miRNAs. Nascent miRNA (pri-miRNA) is generated by RNA polymerase II or III and processed within the nucleus into approximately 70-nucleotide incomplete stem-loop RNA (pre-miRNA) by the RNase III endonuclease Drosha and DGCR8 (Drosha/DGCR8 complex). Exportin 5 transports pre-miRNA from the nucleus to the cytoplasm. 
The cytoplasmic RNase III Dicer then cuts pre-miRNA into a 19-22-base long RNA duplex. RISC (the RNAinduced silencing complex) incorporates the short RNA duplex and activates one strand of RNA (mature miRNA) while the other strand is degraded. The biological role of miRNA is to inactivate single or multiple target genes by sequence-specific binding-mediated mechanisms.

\section{MiRNA and cancer}

Cancer-specific miRNAs and fingerprints have been identified in every type of tumor analyzed [[22••] and [23••]]. To date, numerous miRNAs have been identified as tumor-related and can be categorized in two groups based on their functional relevance. miRNAs that have oncogenic effects/roles are categorized in oncogenic miRNAs (oncomiRs), while miRNAs that have tumor-suppressive effects/roles are categorized in tumorsuppressive miRs (ts-miRs). In normal cells, ts-miRs are highly expressed and downregulate the expression of oncogenic proteins, whereas in tumor cells, ts-miRs are silenced, leading to the upregulation of oncogenic proteins. Conversely, oncomiRs are upregulated in tumor cells, downregulating the expression of tumorsuppressive proteins. For example, the miR-17-92 cluster has been characterized as oncogenic (oncomiRs) [24 L. He, J.M. Thomson, M.T. Hemann, E. Hernando-Monge, D. Mu, S. Goodson, S. Powers, C. Cordon-Cardo, S.W. Lowe and G.J. Hannon et al., A microRNA polycistron as a potential human oncogene, Nature 435 (2005), pp. 828-833. Full Text via CrossRef | View Record in Scopus | Cited By in Scopus (719)24] and miR-21 also has been found to be upregulated in various types of cancers downregulating tumor suppressor genes such as tropomyosin 1 (TPM1), programed cell death 4 (PDCD4), and tissue inhibitor of metalloproteinase 3 (TIMP3) 
[25•], while let-7 represses Ras [26] and miR-15a and miR-16-1 repress Bcl-2 [27], thereby acting as tumor suppressors (ts-miRs).

\section{MiRNA in BE and EAC}

To date, a few miRNA studies have been reported in BE and EAC; however, experimental evidence has steadily elucidated the molecular mechanisms underlying BE and EAC. miRNA expression profiles in BE and EAC were first reported by Feber et al. [28•]. Studying surgical specimens of 10 squamous cell carcinomas of the esophagus, 5 BEs, $1 \mathrm{HGD}$ and 10 EACs as well as 5 normal squamous epithelia (NSE), they successfully demonstrated that miRNA expression patterns discriminated between tissue types. Since miRNA expression profiling has shown to provide more accurate classification of tissue and tumor types than global messenger RNA expression profiles [[29] and [30]], miRNA expression profiling is now a promising method to identify key effectors that play important roles in BE-EAC carcinogenesis. In fact, Feber et al. discovered interesting results in this context. Among the upregulated and downregulated miRNA lists they generated, miR-192, miR194, miR-21, and miR-93 were progressively upregulated during progression from NSE to BE and finally to EAC. miR-192 is upregulated in lung cancer and exerts proliferative effects [31] and is also overexpressed in colon cancer with effects on cell cycle progression [32], suggesting that miR-192 possesses oncogenic (oncomiR) properties. miR-21 is also a well-characterized oncomiR that is upregulated in a number of different cancers [[25•], [33] and [34]]. In contrast, one group revealed that miR-205 was downregulated in both BE and EAC versus NSE, implying tumor-suppressive (ts-miR) properties for this miR. Interestingly, this finding is compatible with our own recent study [35••], which comprises the latest report regarding miRNA dysregulation 
in BE and EAC. miR-205 has also been reported to be downregulated in prostate cancer, where it has been linked to the targeting of PKC epsilon [36] as well as breast cancer where it targets HER3 as well as ErbB3 and VEGF-A [[37] and [38]]. Childs et al. reported that miR-205 (and let-7d) downregulation, was significantly associated with poor survival in head and neck cancer [39], suggesting potential application as prognostic indicators. In view of all the above findings, miR-205 may constitute a good biomarker for BE as well as EAC.

Luthra et al. reported that miR-196a was upregulated in EAC tissues, targeting annexin A1 (ANXA1) [40•]. miR-196a downregulates ANXA1, consequently exerting antiapoptotic effects and contributing to EAC cell survival. This group further pursued this finding, reporting that miR-196a is a good potential biomarker of neoplastic progression in BE, and demonstrating the stepwise upregulation of miR-196a expression during the BE-dysplasia-EAC sequence $[41 \bullet \bullet]$.

Finally, our own group recently reported several miRNA-related mechanisms involved in BE and EAC [35••]. In our initial approach, miRNA microarrays were performed to identify upregulated or downregulated miRNAs in BE-associated lesions. Strikingly, we discovered that miR-25, miR-93, and miR-106b, all of which form a polycistron on chromosome 7q22.1 (the miR-106b-25 polycistron), were progressively activated at successive stages of esophageal neoplasia from normal epithelium to BE and finally to EAC. Upregulation of the miR106b-25 polycistron was also associated with genomic amplification and overexpression of MCM7 (the mother gene containing this polycistron), potentially because of de novo genomic DNA copy number variation involving the MCM7 locus at chromosome 7q22.1. Moreover, the miR-106b-25 polycistron exerted potential 
proliferative, antiapoptotic, and cell cycle-promoting effects in vitro and tumorigenic effects in vivo. We found that miR-93 and miR-106b targeted and inhibited CDKN1A (p21), whereas miR-25 targeted and inhibited Bcl2-like protein 11 (BCL2L11, Bim). The miR-106b-25 polycistron thus represents a likely oncomiR involved in BE-EAC carcinogenic evolution, as well as in other human cancers [[42] and [43]], and may act via the regulation of two specific target genes, p21 and Bim. Representative miRNA expression levels in BE and EAC and their potential target transcripts are shown in Table 1.

\section{Therapeutic/clinical application of miRNAs}

OncomiRs are presumed to function by downregulating tumor suppressor genes. OncomiRs also have the potential to serve as molecular therapeutic targets, since their inhibition should result in increased levels of tumor suppressor proteins [[35••] and [40•]]. Conversely, it can be postulated that re-introduction of ts-miRs into tumor cells will result in the downregulation of target oncogenes, causing tumor suppression [[37], [44] and [45]]. At present, there are no reports of the use of miRNA for anticancer therapy in the clinical field. However, miRNA-based gene therapy provides an attractive antitumor approach for integrated cancer therapy [46•]. One advantage of miRNAs over siRNAs/shRNAs is that miRNAs target multiple genes simultaneously, powerfully inactivating entire pathways at once. This effect contrasts markedly with the unpredictable and undesirable offtarget effects of siRNAs/shRNAs. Emerging reports on miRNAs in BE and EAC have suggested that miRNAs are promising in categorizing BE-associated lesions (including dysplasia) into subgroups, stratifying the risk of susceptibility to developing EAC, diagnosing EAC, and developing future therapeutic targets in BE and EAC. 


\section{$<$ Conclusions $>$}

Recent gains in our knowledge of miRNA expression and its role in BE and EAC have considerably advanced our understanding of the molecular mechanisms underlying BE-associated neoplasia. miRNA profiling shows promise as an accurate diagnostic tool, and BE-specific or EAC-specific miRNAs may eventually constitute useful biomarkers as well as therapeutic targets.

\section{<Acknowledgements $>$}

This work was supported partially by NIH awards CA085069, CA01808, and CA146799.

\section{$<$ Conflicts of Interest $>$}

The authors have no conflicts to disclose. 
$<$ References and recommended reading $>$

Papers of particular interest, published within the annual period of review, have been highlighted as:

- of special interest

- of outstanding interest

1. Cameron AJ: Management of Barrett's esophagus. Mayo Clin Proc (1998) 73(5):457-461.

2. Jankowski JA, Wright NA, Meltzer SJ, Triadafilopoulos G, Geboes K, Casson AG, Kerr D, Young LS:

Molecular evolution of the metaplasia-dysplasia-adenocarcinoma sequence in the esophagus. Am $J$ Pathol (1999) 154(4):965-973.

3. Selaru FM, Zou T, Xu Y, Shustova V, Yin J, Mori Y, Sato F, Wang S, Olaru A, Shibata D et al: Global gene expression profiling in Barrett's esophagus and esophageal cancer: a comparative analysis using cDNA microarrays. Oncogene (2002) 21(3):475-478.

4. Kimos MC, Wang S, Borkowski A, Yang GY, Yang CS, Perry K, Olaru A, Deacu E, Sterian A, Cottrell $\mathrm{J}$ et al: Esophagin and proliferating cell nuclear antigen (PCNA) are biomarkers of human esophageal neoplastic progression. Int J Cancer (2004) 111(3):415-417. 
5. Schulmann K, Sterian A, Berki A, Yin J, Sato F, Xu Y, Olaru A, Wang S, Mori Y, Deacu E et al: Inactivation of p16, RUNX3, and HPP1 occurs early in Barrett's-associated neoplastic progression and predicts progression risk. Oncogene (2005) 24(25):4138-4148.

6. Carninci P, Kasukawa T, Katayama S, Gough J, Frith MC, Maeda N, Oyama R, Ravasi T, Lenhard B, Wells C et al: The transcriptional landscape of the mammalian genome. Science (2005) 309(5740):1559-1563.

7. Lewis BP, Burge CB, Bartel DP: Conserved seed pairing, often flanked by adenosines, indicates that thousands of human genes are microRNA targets. Cell (2005) 120(1):15-20.

8. Lagergren J: Etiology and risk factors for oesophageal adenocarcinoma: possibilities for chemoprophylaxis? Best Pract Res Clin Gastroenterol (2006) 20(5):803-812.

9. Cameron AJ, Lomboy CT: Barrett's esophagus: age, prevalence, and extent of columnar epithelium. Gastroenterology (1992) 103(4):1241-1245.

10. Hirota WK, Loughney TM, Lazas DJ, Maydonovitch CL, Rholl V, Wong RK: Specialized intestinal metaplasia, dysplasia, and cancer of the esophagus and esophagogastric junction: prevalence and clinical data. Gastroenterology (1999) 116(2):277-285. 
11. Ronkainen J, Aro P, Storskrubb T, Johansson SE, Lind T, Bolling-Sternevald E, Vieth M, Stolte M, Talley NJ, Agreus L: Prevalence of Barrett's esophagus in the general population: an endoscopic study. Gastroenterology (2005) 129(6):1825-1831.

12. Sampliner RE: A population prevalence of Barrett's esophagus--finally. Gastroenterology (2005) 129(6):2101-2103.

13. van Soest EM, Dieleman JP, Siersema PD, Sturkenboom MC, Kuipers EJ: Increasing incidence of Barrett's oesophagus in the general population. Gut (2005) 54(8):1062-1066.

- 14. Shaheen NJ, Richter JE: Barrett's oesophagus. Lancet (2009) 373(9666):850-861.

The latest review of the Barrett's esophagus. The authors review the presentation, epidemiology, and risk factors for this condition. They also assess the effectiveness of efforts to screen patients at risk of Barrett's oesophagus, and whether such efforts avert cancer death.

15. Inadomi JM: Surveillance in Barrett's esophagus: a failed premise. Keio J Med (2009) 58(1):12-18. 
16. Dulai GS, Guha S, Kahn KL, Gornbein J, Weinstein WM: Preoperative prevalence of Barrett's esophagus in esophageal adenocarcinoma: a systematic review. Gastroenterology (2002) 122(1):2633.

- 17. Kim VN, Han J, Siomi MC: Biogenesis of small RNAs in animals. Nat Rev Mol Cell Biol (2009) 10(2):126-139.

The authors describe the biogenesis of small RNAs in animals. This Review summarizes the current knowledge of how these intriguing molecules are generated in animal cells.

18. Lee Y, Kim M, Han J, Yeom KH, Lee S, Baek SH, Kim VN: MicroRNA genes are transcribed by RNA polymerase II. Embo J (2004) 23(20):4051-4060.

19. Borchert GM, Lanier W, Davidson BL: RNA polymerase III transcribes human microRNAs. Nat Struct Mol Biol (2006) 13(12):1097-1101.

20. Gregory RI, Yan KP, Amuthan G, Chendrimada T, Doratotaj B, Cooch N, Shiekhattar R: The Microprocessor complex mediates the genesis of microRNAs. Nature (2004) 432(7014):235-240.

21. Lee Y, Ahn C, Han J, Choi H, Kim J, Yim J, Lee J, Provost P, Radmark O, Kim S et al: The nuclear RNase III Drosha initiates microRNA processing. Nature (2003) 425(6956):415-419. 
• 22. Visone R, Croce CM: MiRNAs and cancer. Am J Pathol (2009) 174(4):1131-1138.

This article reviews the current knowledge about miRNAs, focusing on their involvement in cancer and their potential as diagnostic, prognostic, and therapeutic tools.

• 23. Bartels CL, Tsongalis GJ: MicroRNAs: novel biomarkers for human cancer. Clin Chem (2009) 55(4):623-631.

In this review, the authors describe the structure, nomenclature, mechanism of action, technologies used for miRNA detection, and associations of miRNAs with human cancer, especially focused in terms of boimarkers.

24. He L, Thomson JM, Hemann MT, Hernando-Monge E, Mu D, Goodson S, Powers S, Cordon-Cardo C, Lowe SW, Hannon GJ et al: A microRNA polycistron as a potential human oncogene. Nature (2005) 435(7043):828-833.

- 25. Selaru FM, Olaru AV, Kan T, David S, Cheng Y, Mori Y, Yang J, Paun B, Jin Z, Agarwal R et al: MicroRNA-21 is overexpressed in human cholangiocarcinoma and regulates programmed cell death 4 and tissue inhibitor of metalloproteinase 3. Hepatology (2009) 49(5):1595-1601.

The first report of miRNA in human cholangiocarcinoma (CCA). MiR-21 is overexpressed in human CCAs, inhibiting PDCD4 and TIMP3. MiR-21 was 95\% sensitive and 100\% specific in distinguishing between CCA and normal tissues, with an area under the receiver operating characteristic curve of 0.995. 
26. Johnson SM, Grosshans H, Shingara J, Byrom M, Jarvis R, Cheng A, Labourier E, Reinert KL, Brown D, Slack FJ: RAS is regulated by the let-7 microRNA family. Cell (2005) 120(5):635-647.

27. Cimmino A, Calin GA, Fabbri M, Iorio MV, Ferracin M, Shimizu M, Wojcik SE, Aqeilan RI, Zupo S, Dono $\mathrm{M}$ et al: miR-15 and miR-16 induce apoptosis by targeting BCL2. Proc Natl Acad Sci U S A (2005) 102(39):13944-13949.

- 28. Feber A, Xi L, Luketich JD, Pennathur A, Landreneau RJ, Wu M, Swanson SJ, Godfrey TE, Litle VR: MicroRNA expression profiles of esophageal cancer. J Thorac Cardiovasc Surg (2008) 135(2):255260; discussion 260.

The first report of miRNA expression profiles in esophageal cancer. The authors revealed that expression profiles of miRNA distinguish esophageal tumor histology and can discriminate normal tissue from tumor.

29. Lu J, Getz G, Miska EA, Alvarez-Saavedra E, Lamb J, Peck D, Sweet-Cordero A, Ebert BL, Mak RH, Ferrando AA et al: MicroRNA expression profiles classify human cancers. Nature (2005) 435(7043):834-838. 
30. Calin GA, Ferracin M, Cimmino A, Di Leva G, Shimizu M, Wojcik SE, Iorio MV, Visone R, Sever NI, Fabbri $\mathrm{M}$ et al: A MicroRNA signature associated with prognosis and progression in chronic lymphocytic leukemia. N Engl J Med (2005) 353(17):1793-1801.

31. Cheng AM, Byrom MW, Shelton J, Ford LP: Antisense inhibition of human miRNAs and indications for an involvement of miRNA in cell growth and apoptosis. Nucleic Acids Res (2005) 33(4):12901297.

32. Song B, Wang Y, Kudo K, Gavin EJ, Xi Y, Ju J: miR-192 Regulates dihydrofolate reductase and cellular proliferation through the p53-microRNA circuit. Clin Cancer Res (2008) 14(24):8080-8086.

33. Gramantieri L, Fornari F, Callegari E, Sabbioni S, Lanza G, Croce CM, Bolondi L, Negrini M: MicroRNA involvement in hepatocellular carcinoma. J Cell Mol Med (2008) 12(6A):2189-2204.

34. Moriyama T, Ohuchida K, Mizumoto K, Yu J, Sato N, Nabae T, Takahata S, Toma H, Nagai E, Tanaka M: MicroRNA-21 modulates biological functions of pancreatic cancer cells including their proliferation, invasion, and chemoresistance. Mol Cancer Ther (2009). 
• 35. Kan T, Sato F, Ito T, Matsumura N, David S, Cheng Y, Agarwal R, Paun BC, Jin Z, Olaru AV et al: The miR-106b-25 polycistron, activated by genomic amplification, functions as an oncogene by suppressing p21 and Bim. Gastroenterology (2009) 136(5):1689-1700.

Report of the novel findings of the miR-106b-25 polycistron in esophageal neoplastic progression. This polycistron is upregulated progressively at successive stages of neoplasia, in association with genomic amplification and overexpression of MCM7, and involved in the proliferation via suppression of 2 target genes: p21 and Bim.

36. Gandellini P, Folini M, Longoni N, Pennati M, Binda M, Colecchia M, Salvioni R, Supino R, Moretti R, Limonta $\mathrm{P}$ et al: miR-205 Exerts tumor-suppressive functions in human prostate through downregulation of protein kinase Cepsilon. Cancer Res (2009) 69(6):2287-2295.

37. Iorio MV, Casalini P, Piovan C, Di Leva G, Merlo A, Triulzi T, Menard S, Croce CM, Tagliabue E: microRNA-205 regulates HER3 in human breast cancer. Cancer Res (2009) 69(6):2195-2200.

38. Wu H, Zhu S, Mo YY: Suppression of cell growth and invasion by miR-205 in breast cancer. Cell Res (2009) 19(4):439-448. 
39. Childs G, Fazzari M, Kung G, Kawachi N, Brandwein-Gensler M, McLemore M, Chen Q, Burk RD, Smith RV, Prystowsky MB et al: Low-level expression of microRNAs let-7d and miR-205 are prognostic markers of head and neck squamous cell carcinoma. Am J Pathol (2009) 174(3):736-745.

- 40. Luthra R, Singh RR, Luthra MG, Li YX, Hannah C, Romans AM, Barkoh BA, Chen SS, Ensor J, Maru DM et al: MicroRNA-196a targets annexin A1: a microRNA-mediated mechanism of annexin A1 downregulation in cancers. Oncogene (2008) 27(52):6667-6678.

This study reports that miR-196a promoted cell proliferation, anchorage-independent growth and suppressed apoptosis, via targeting ANXA1 expression, suggesting its oncogenic potential.

• 41. Maru DM, Singh RR, Hannah C, Albarracin CT, Li YX, Abraham R, Romans AM, Yao H, Luthra MG, Anandasabapathy S et al: MicroRNA-196a is a potential marker of progression during Barrett's metaplasia-dysplasia-invasive adenocarcinoma sequence in esophagus. Am J Pathol (2009) 174(5):1940-1948.

This study identified miR-196a as a potential marker of progression of BE. KRT5, SPRR2C, and S100A9 are targets of the miR-196a.

42. Ivanovska I, Ball AS, Diaz RL, Magnus JF, Kibukawa M, Schelter JM, Kobayashi SV, Lim L, Burchard J, Jackson AL et al: MicroRNAs in the miR-106b family regulate p21/CDKN1A and promote cell cycle progression. Mol Cell Biol (2008) 28(7):2167-2174. 
43. Petrocca F, Visone R, Onelli MR, Shah MH, Nicoloso MS, de Martino I, Iliopoulos D, Pilozzi E, Liu CG, Negrini M et al: E2F1-regulated microRNAs impair TGFbeta-dependent cell-cycle arrest and apoptosis in gastric cancer. Cancer Cell (2008) 13(3):272-286.

44. Akao $\mathrm{Y}$, Nakagawa $\mathrm{Y}$, Naoe $\mathrm{T}$ : let-7 microRNA functions as a potential growth suppressor in human colon cancer cells. Biol Pharm Bull (2006) 29(5):903-906.

45. Scott GK, Goga A, Bhaumik D, Berger CE, Sullivan CS, Benz CC: Coordinate suppression of ERBB2 and ERBB3 by enforced expression of micro-RNA miR-125a or miR-125b. J Biol Chem (2007) 282(2):1479-1486.

- 46. Wang V, Wu W: MicroRNA-based therapeutics for cancer. BioDrugs (2009) 23(1):15-23.

In this review, the authors focus on miRNA-based treatment for cancers, summarize the delivery systems used in experimental and preclinical research, and consider the safety and toxicity of miRNA therapy. MiRNA-based gene therapy provides an attractive anti-tumor approach for integrated cancer therapy. 


\section{$<$ Figure legends and Table notes $>$}

Figure 1. Biogenesis of the miRNAs. Nascent miRNA (pri-miRNA) is generated by RNA polymerase II or III and processed within the nucleus into approximately 70-nucleotide incomplete stem-loop RNA (pre-miRNA) by the RNase III endonuclease Drosha and DGCR8 (Drosha/DGCR8 complex). Exportin 5 transports premiRNA from the nucleus to the cytoplasm. The cytoplasmic RNase III Dicer then cuts pre-miRNA into a 1922-base long RNA duplex. RISC (the RNA-induced silencing complex) incorporates the short RNA duplex and activates one strand of RNA (mature miRNA) while the other strand is degraded. The biological role of miRNA is to inactivate single or multiple target genes by sequence-specific binding-mediated mechanisms.

Table 1. Data were from the following references: [28] [35] [41]. \# indicates stepwise expression in Barrett's esophagus and esophageal adenocarcinoma from normal squamous epithelium 


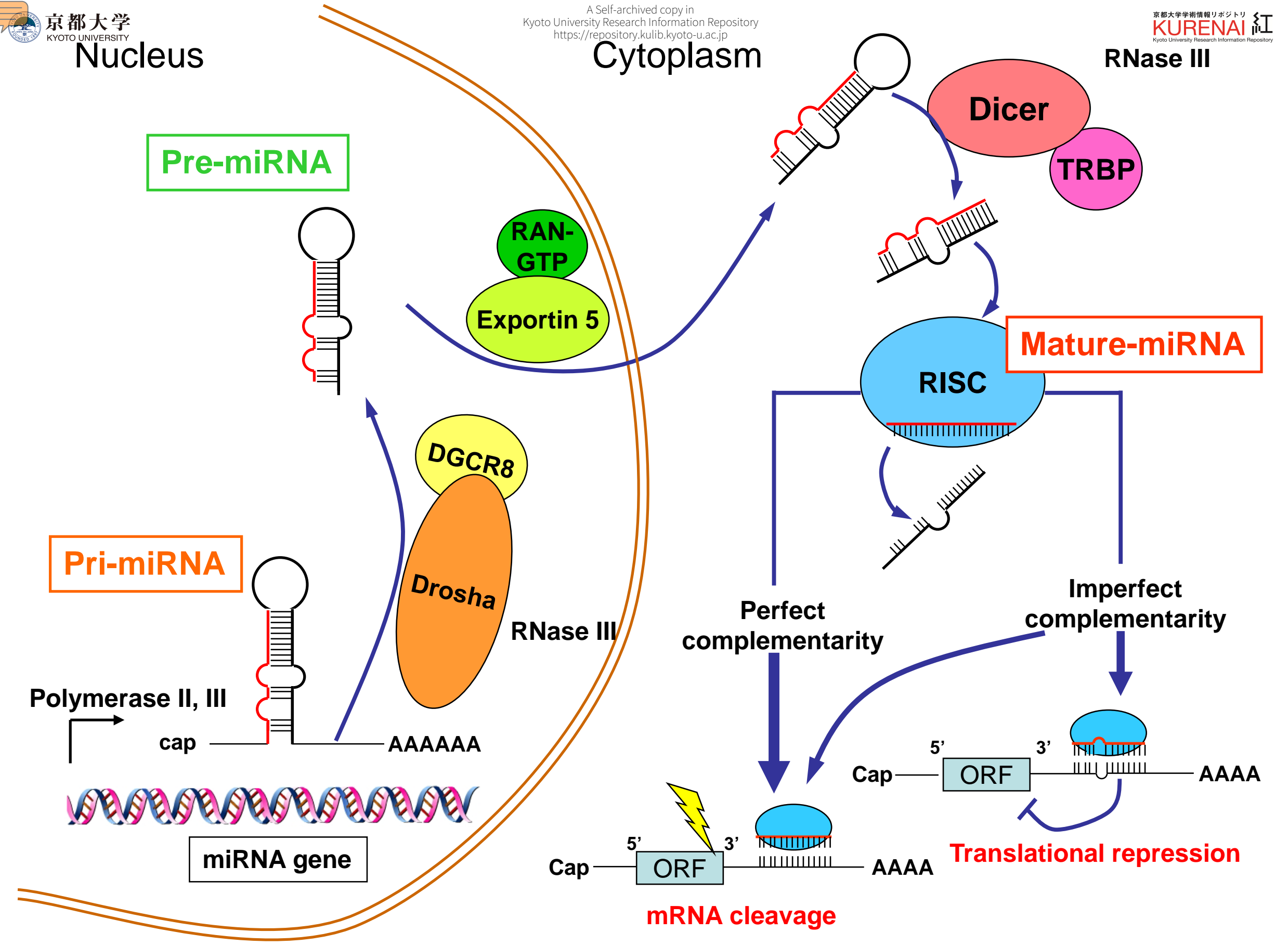




\begin{tabular}{|c|c|c|c|}
\hline Barrett's Esophagus & Esophageal Adenocarcinoma & Potential Target Transcripts & Functions \\
\hline $\mathrm{miR}-21$ & $\mathrm{miR}-21$ & $\begin{array}{l}\text { BMPRII, LRRF1P1, BTG2, PTEN, } \\
\text { PDCD4, TM1, MARCKS, TIMP3 }\end{array}$ & $\begin{array}{c}\text { Cell cycle, Cell proliferation, } \\
\text { Apoptosis }\end{array}$ \\
\hline $\operatorname{miR}-192^{\#}$ & $\operatorname{miR}-192^{\#}$ & $\begin{array}{c}\text { DHFR, CDC7, LMNB2, MAD2L1, } \\
\text { CUL5 }\end{array}$ & Cell cycle, Cell proliferation \\
\hline $\mathrm{miR}-194^{\#}$ & $\operatorname{miR}-194^{\#}$ & EP300 & Metastasis \\
\hline$m i R-200 c$ & $\mathrm{miR}-200 \mathrm{c}$ & ZEB1, ZEB2, TUBB3 & $\begin{array}{c}\text { Epithelial-mesenchymal } \\
\text { transition (EMT) }\end{array}$ \\
\hline $\mathrm{miR}-196 \mathrm{a}^{\#}$ & $\mathrm{miR}-196 \mathrm{a}^{\#}$ & ANXA1, KRT5, SPRR2C, S100A9 & $\begin{array}{c}\text { ANXA1, KRT5, SPRR2C, } \\
\text { S100A9 }\end{array}$ \\
\hline \multirow[t]{3}{*}{$\mathrm{miR}-25^{\#}$} & $\mathrm{miR}-25^{\#}$ & BCL2L11 & Apoptosis \\
\hline & $\mathrm{miR}-93$ & CDKN1A & Cell cycle \\
\hline & $m i R-106 b$ & CDKN1A & Cell cycle \\
\hline
\end{tabular}

Downregulated miRNAs

\begin{tabular}{|c|c|c|c|}
\hline Barrett's Esophagus & Esophageal Adenocarcinoma & Potential Target Transcripts & Functions \\
\hline & miR-205 & HER3, PRKCD, VEGFA & Cell proliferation, EMT \\
\hline & $\mathrm{miR}-203$ & ABL1, TP63 & Cell proliferation \\
\hline & $\mathrm{miR}-27 \mathrm{~b}$ & ST14, CYP1B1 & $\begin{array}{c}\text { Cell proliferation, Cell } \\
\text { migration, invasion, Drug } \\
\text { metabolism }\end{array}$ \\
\hline \multirow[t]{3}{*}{$\mathrm{miR}-125 \mathrm{~b}$} & $\mathrm{miR}-125 b$ & CYP24, ERBB2, ERBB3 & Cell proliferation \\
\hline & $\operatorname{miR}-100$ & FRAP1, RPTOR & CMV replication \\
\hline & $m i R-19 b$ & $\begin{array}{l}\text { E2F1, MYC, BCL2L11, CDKN1A, } \\
\text { HIF1 }\end{array}$ & $\begin{array}{l}\text { Cell proliferation, Apoptosis, } \\
\text { Cell cycle }\end{array}$ \\
\hline
\end{tabular}

